\title{
THE GOALS OF ARCHAEOLOGY, IN THEORY: WHAT ARE WE TRYING TO DO?
}

Matthew H. Johnson

Northwestern University

Department of Anthropology

1810 Hinman Ave., Evanston, IL 60208-1310, USA

matthew-johnson@northwestern.edu

Gavin Lucas has written a keynote paper that I find to be intelligent, thoughtful, and clearly written. Its conversational tone is refreshingly free from bombast, claims of absolute academic authority, and dogmatism. It is strikingly fair to all parties (indeed, it is perhaps a little too kind to some) and it does not seek to redline, dismiss, or denigrate those who might disagree.

He has also written a paper in whose main elements I find much to agree with. I like the emphasis in this paper on bottom-up rather than top-down theorizing, or more accurately the interdependence of these processes. I like the implication that theory could or should emerge from field practice, and reflection upon field practice, rather than be imposed upon it unilaterally. As a pragmatist, my first response to any belief or theoretical position is to ask about its practical consequences in the world. Lucas places such a concern at centre stage.

Let me enumerate a couple of areas of respectful disagreement. First, I am not fully persuaded that "borrowing" of theory has been as prevalent as Lucas implies. It is certainly true that many archaeologists frequently complain about this, but what they overlook in my view is that theory is by its very nature interdisciplinary. As Culler states, "The genre of 'theory' includes works of anthropology, art history, film studies, gen- 
der studies, linguistics, philosophy, political theory, psychoanalysis, science studies, social and intellectual history, and sociology. The works in question are tied to arguments in these fields, but they become 'theory' because their visions or arguments have been suggestive or productive for people who are not studying those disciplines" (Culler 1997:4; of course, Culler doesn't cite archaeology). Consequently it will always appear "borrowed". Which discipline sees Foucault as "their" theorist? Certainly not historians, who remain a traditional bunch by their own enthusiastic affirmation (cf. Evans 2000, a resolutely anti-theoretical book that was panned by theorists but given consistently excellent reviews by traditional historians themselves).

Second, the (claimed) loss of the edge of the r980s need not imply boredom in the contemporary scene; rather the reverse. As someone who participated in the debates of the 1980 s, both in terms of its archaeology and its politics, I can testify that while there was great excitement and a feeling of profound change afoot, there was also a lot of boredom about at the time, much of it felt by those unfortunate enough to be in the audience when some of those now waxing nostalgic were giving papers. There was a lot of shouting in the I980s on all sides, but shouting is not necessarily the same thing as critical edge, and looking back thirty years later, we might be a little more reflexive about who was being marginalized or excluded by the often excessively pugnacious tone of the debate (cf. Conkey 2007). I suspect that when historians of archaeology come to write about this period, they will isolate its growing consciousness of issues of diversity - who gets to say what about the past, who is excluded and who is included - as the most important and positive aspect of that decade. Looking around the archaeological landscape today, I do not see crisis or boredom; I see a huge variety of exciting work taking place (admittedly, alongside some less exciting work, cf. Kintigh et al. discussed below). Perhaps they are just being very polite, but my students do not seem bored when they engage with a range of current research.

But why am I finding it so hard to frame a more general response to the paper?

A first reason is that I am partly unsure what I can possibly take issue with. The paper is too balanced, too fair. For each view that Lucas proposes, he immediately frames a counter-view. Theory could or should be bottom-up - but then again, perhaps it could or should be top-down as well. It is a bad thing if theory is borrowed - but then again, it may not be so bad after all. There is also a fluidity to the argument that is quite enabling, like the concept-metaphors Lucas discusses. As he states, these concept-metaphors have intellectual purchase and utility precisely because they are ambiguous and capable of adaptation to multiple themes 
or positions. Ultimately, then, it is difficult to define a provocative position that the paper takes in relation to which I can frame a response.

A second, deeper reason is that Lucas does not define theory. There are good reasons for this decision. Attempts to define theory are all too frequently associated with attempts to delimit its parameters, and/or impose a particularly positivist view in which, having been placed outside the purview of a delimited theory, facts can be said to exist or to speak for themselves. As a result, however, his argument, a sense of where specifically Lucas is trying to go intellectually in this article, becomes quite slippery and difficult to grasp.

A third, deeper reason still is that there is a central element missing from the argument, an element which is often taken as commonsensical or taken-for-granted but which within the intellectual frame adopted by Lucas needs interrogation. Namely: Lucas does not state what he thinks the goals of archaeology are or might be.

Of course, Lucas might reasonably respond that he is trying to frame a bottom-up view of theory rather than a top-down view, and therefore work from the processes of excavation and field research upwards rather than from overall disciplinary goals downwards. I sympathize with this turn, but as Lucas implies elsewhere in the paper, it's an endlessly recursive process.

Take his example at the beginning of his paper, the everyday practices of excavation of a twentieth-century Icelandic fishing site. What brought us to this place - why we are digging this site? Why look at something so very recent? Lucas talks about where all the stuff went - is the aim to find out "what really happened" at this place? Is the aim to produce some general observations on modern material culture? Or to provide a wider meditation on the present? The possible answers one might give to these questions imply in their turn the choice of different theories to develop and techniques to employ at the site.

Perhaps I am mistaken, but given the tone of the article, and given Lucas's other writings, I would expect Lucas to be agnostic about what the goals of archaeology could or should be. In this paper and in his excellent book Understanding the Archaeological Record, Lucas seems to me to be more interested in teasing out the implications, tensions and differences in others' views of a given subject than necessarily articulating and defending a view of his own. Again, there's nothing wrong with this. But different views of the goals of archaeology are as varied, and various, as the different outlooks on theory discussed in his paper. Compare, for example, the "goals of archaeology" as suggested by different keynotes in Current Swedish Archaeology. Olsen seems to have given up the large-scale explanation or understanding of the past as a 
primary goal. In response, Holtorf comments that for him, and for most of us, "archaeology is mainly the study of the past and its remains in the present" (Olsen 20I2; Holtorf 2OI2). Kristiansen retains a faith in the large scale, in scientific modes of explanation, and the need for and capacity of archaeology to engage with large-scale, fundamental questions of humanity (Kristiansen 20I4).

All of these views of the goals of archaeology are at a remove, again, from still other views. Consider the "grand challenges" outlined in Kintigh et al. 20I4, the product of a crowdsourcing exercise that claims to derive from both North American and European sources but which ends up being decidedly North American and processual in thrust and tone. As Cobb (20I4) has noted, the challenges facing archaeology outlined here are largely described as transhistorical in nature. Writing himself from within a North American perspective, Cobb points out the lack of reference in Kintigh et al. to the goals of archaeology as articulated by culture history, in terms of periods/areas/questions. He also points out the relative lack of political commitment and framing in this document. Interestingly, the "grand challenges" paper and Cobb's response to it follow a very similar pattern to the debate ten years ago in American Antiquity, when Michelle Hegmon's characterization of a "processualplus" mainstream orthodoxy in North American archaeology drew dissenting views from feminist and Indigenous scholars (Hegmon 2003; Watkins 2003; Moss 2005).

This isn't the place to attempt to adjudicate between these different positions on our goals; nor is it the place to propose a synthesis or reconciliation (if such a thing were possible or even desirable). But it is the place to point out that each set of goals implies a different definition of what theory is, and a different set of propositions about what theory is for.

Most obviously, Binford's conception and deployment of middlerange theory, and its close relationship to what he calls actualistic research, only makes sense in relation to a broadly positivist conception of what general theory is or should be. Here, I wonder whether Lucas's engagement with Merton's work is a red herring: I am unsure that there is any real relationship between Merton's middle-range theory and that of Binford's, other than a linguistic similarity. I only know of a single reference in Binford's work to that of Merton, and that a very brief reference that implies both an (openly admitted) lack of knowledge of Merton's work and also a distancing from it, or at least a distancing from its secondary use in archaeology (Binford 1977:I9). Lucas may well be accurate in claiming that Merton's conception of MRT has something to offer archaeology... though of course, this may be another potentially problematic borrowing from another discipline. 
So I have a question for Lucas in his response. What, in your view, could or should the goals of archaeology be? Theory is important, but it is not everything - theory links up what one is trying to say with the material record that is the evidential basis and foundation for those statements. What is it that are we trying to say?

\section{ACKNOWLEDGEMENTS}

I thank Mark Hauser for conversations that informed the content of this response.

\section{REFERENCES}

\section{Literature}

Binford, L. R. 1977. Bones: Ancient Men and Modern Myths. New York: Academic Press.

Cobb, C. R. 20I4. The Once and Future Archaeology. American Antiquity. Vol. 79:4. Pp. 589-595.

Conkey, M. 2007. Questioning Theory: Is There a Gender of Theory in Archaeology? Journal of Archaeological Method and Theory. Vol. i4. Pp. 285-3Io.

Culler, J. 1997. Literary Theory: A Very Short Introduction. Oxford, Oxford University Press.

Evans, R. J. 2000. In Defence of History. New York: Norton.

Hegmon, M. 2003. Setting Theoretical Egos Aside: Issues and Theory in North American Archaeology. American Antiquity. Vol. 68:2. Pp. 213-243.

Holtorf, C. 20I 2. No Farewell to Interpretation. Current Swedish Archaeology. Vol. 20. Pp. 57-60.

Kintigh, K., Altschul, J. H., Beaudry, M. C., Drennan, R. D., Kinzig, A. P., Kohler, T. A., Limp, F. W., Maschner, H. D. G., Michener, W. K., Pauketat, T. R., Peregrine, P., Sabloff, J. A., Wilkinson, T. J., Wright, H. T. \& Zeder, M. A. 20I4. Grand Challenges for Archaeology. American Antiquity. Vol. 79:I. Pp. 5-24.

Kristiansen, K. 20I4. Towards a New Paradigm? The Third Science Revolution and its Possible Consequences in Archaeology. Current Swedish Archaeology. Vol. 22. Pp. II 34 .

Lucas, G. 20I 2. Understanding the Archaeological Record. Cambridge University Press.

Moss, M. 2005. Rifts in the Theoretical Landscape of Archaeology in the United States: A Comment on Hegmon and Watkins. American Antiquity. Vol. 70:3. Pp. $58 \mathrm{I}-587$.

Watkins, J. 2003. Beyond the Margin: American Indians, First Nations, and Archaeology in North America. American Antiquity. Vol. 68. Pp. 273-285.

Olsen, B. 20I 2. After Interpretation: Remembering Archaeology. Current Swedish Archaeology. Vol. I5/I6. Pp. II-34. 